\title{
INTERAÇÃO E INTERDISCIPLINARIDADE EM TEMPOS DA COVID-19
}

\author{
Leila Laís Gonçalves \\ Elenice Padoin Juliani Engel \\ DOI: http://dx.doi.org/10.18616/intcov33
}

A interdisciplinaridade, como prática pedagógica, visa promover a interação entre o aluno, o professor, os saberes e o cotidiano buscando superar a fragmentação do conhecimento, condição fundamental do ensino, da pesquisa e da extensão no mundo contemporâneo. Partindo do pressuposto que as formas de conhecer são dialógicas e se interpenetram, as práticas que agregam o conhecimento do senso comum e que se ampliam com o conhecimento científico permitem enriquecer as relações entre os envolvidos e tendem a uma dimensão maior na construção de sentido e significado no processo de ensino e aprendizagem (GIBBONS et al., 1997). Entende-se que nesse processo a interação entre os agentes no ecossistema educacional é ponto-chave na dinâmica interdisciplinar.

Os cursos Educação a Distância (EAD) da Universidade do Extremo Sul Catarinense (UNESC) desenvolvem uma atividade fundamental no percurso formativo e um dos diferenciais da metodologia EAD, denominada Dinâmica Interdisciplinar Presencial (DIP). A DIP visa à aplicação dos conhecimentos desenvolvidos em cada disciplina do nível e sua articulação com práticas sociais e do mundo do trabalho, buscando resolver situações complexas e exercitar a interação entre os acadêmicos, professores e comunidade.

Em tempos de excepcionalidade, como o da pandemia da covid-19, que tem exigido o isolamento social com mudanças significativas nos comportamentos das pessoas, espaços físicos e práticas para a garantia da biossegurança, faz-se necessário repensar a interação nas intervenções pedagógicas interdisciplinares. Nesse sentido, os professores dos cursos EAD da UNESC da área de ciências sociais aplicadas (CSA) foram desafiados a reestruturar a atividade da DIP. 
A reconfiguração da DIP foi realizada a partir de uma construção coletiva dos professores do nível de formação resultando na proposição de uma dinâmica interdisciplinar on-line com o tema: soluções colaborativas em tempos da covid-19: um olhar socioeconômico. As principais transformações envolveram mudança de locus (do presencial para o on-line), de temporalidade (de um dia para o período de um mês), no processo de execução, uso de tecnologia de comunicação e informação e a participação do curso de Ciência da Computação. A dinâmica foi planejada em cinco etapas: 1) comunicação aos acadêmicos com a provocação do tema; 2) proposição de soluções pelos acadêmicos; 3) seleção de propostas com maior impacto; 4) implementação, impulsionamento e monitoramento das soluções; 5) avaliação, socialização e entrega dos resultados.

Os acadêmicos dos cursos da CSA-EAD propuseram campanhas do tipo vaquinha para arrecadar fundos buscando solucionar um problema socioeconômico de uma instituição local relacionado à pandemia covid-19. Os acadêmicos de Ciência da Computação ficaram responsáveis pela implementação, monitoramento e análise das campanhas. A dinâmica interdisciplinar on-line envolveu cinco disciplinas, seis professores, 84 acadêmicos, cinco instituições sem fins lucrativos, e a implementação de cinco campanhas. As interações ocorreram por meio de web conferência via Google Meet, uso de plataforma on-line de crowdfunding para a arrecadação, redes sociais para impulsionamento das campanhas e ferramentas de social listening para monitoramento e análise das campanhas.

Os desafios impostos pela pandemia covid-19 são diversos, porém conta-se com inúmeras possibilidades de superação. As transformações nas formas de interação, mediadas pelas tecnologias, possibilita reconfigurações necessárias para a continuidade das intervenções pedagógicas, em especial as apoiadas na interdisciplinaridade e na extensão.

\section{REFERÊNCIAS}

GIBBONS, Michael et al. La nueva producción del conocimiento: la dinámica de la ciencia y la investigación en las sociedades contemporáneas. Barcelona: Pomares-Corredor, 1997. 